\title{
El Procedimiento Abreviado como una forma de Descongestión del Sistema Judicial Penal
}

\author{
The Abbreviated Procedure as a form of Disqualification \\ of the Criminal Judicial System
}

\author{
Dr. Guillermo Enríquez Burbano \\ Profesor Titular PUCE (Facultad de Jurisprudencia)
}

Artículo Original (Investigación)

RFJ, No. 2, 2017, pp. 195-231, ISSN 2588-0837

\begin{abstract}
RESUMEN: la presente investigación aborda un estudio claro y conciso en el cual se manifiestan las falencias existentes en el sistema penal ecuatoriano con respecto al procedimiento abreviado, destacándose como un instrumento de agilización y de defensa social a través del cual, se logra una resolución efectiva del conflicto. Es de destacar que el procedimiento abreviado en Ecuador posibilita materializar un causa eficiente, eficaz y efectiva, logrando al mismo tiempo una reactivación del aparato punitivo del Estado, el cual, actualmente es víctima del colapso de la administración de la justicia penal, tomándose en cuenta que la mayoría de casos son ventilados en procedimientos ordinarios, los cuales demandan tiempo, recursos y personal limitados. Por otra parte, el procedimiento abreviado solidifica el proceso de autonomía de la voluntad o del consenso en la resolución de conflictos jurídico penales, logrando en común acuerdo imponer la pena al procesado.
\end{abstract}

PALABRAS CLAVES: justicia, debido proceso, procedimiento abreviado, proceso penal, congestión, disputa legal.

ABSTRACT: the current research is a clear and concise study with failures of the Ecuadorian penal system in respect to the abbreviated proceeding, that is a speed-up instrument and social defense, through which an effective resolution of the conflict is got. The abbreviated proceeding in Ecuador made possible getting an efficient and effective process, with a reactivation of the State punishment apparatus, which currently is a victim of the penal justice collapse, taking into account that out of cases managed in ordinary procedures, which takes time, resources and personnel, restrained nowadays. On the other hand, 
abbreviated proceeding consolidates the autonomy process of the will or consensus in the resolution of juridical-penal conflicts, and penalty is imposed in common agreement.

KEY WORDS: justice, due process, abbreviated procedure, penal process, crowding, legal dispute.

\section{INTRODUCCIÓN}

En la actualidad los índices de seguridad ciudadana se han visto afectados por el incremento de manifestaciones delictivas, las cuales no existían en el siglo pasado, incorporándose nuevas modalidades como el secuestro extorsivo y el sicariato, elementos que han hecho patente la pujanza del hampa en la sociedad ecuatoriana.

Casal (2011), en su obra "Acceso a la Justicia”, explica que la seguridad debe entenderse como la situación en la que el Estado y la sociedad se encuentren protegidos frente a amenazas o riesgos susceptibles de afectar el desarrollo integral y el bienestar de sus ciudadanos, así como el libre ejercicio de sus Derechos y libertades en un contexto de plena vigencia democrática, con miras a alcanzar el buen vivir.

En tal sentido, el Estado y las instituciones han adoptado una serie de decisiones que buscan establecer un espacio de seguridad para el ciudadano en cuyos instrumentos se señala la necesidad de diseñar y establecer sistemas de información que permitan conocer, sobre la base de la evidencia, las distintas manifestaciones que afectan la seguridad del país.

Con estos argumentos se debe adoptar un programa de armonización sobre seguridad como un medio concreto para evaluar y monitorear el progreso de las políticas y sustentar nuevas iniciativas en el ámbito de la seguridad que permita visualizar no solo una situación en el tiempo, sino una tendencia que sustente una definición y acción política sobre el particular.

García (2012), en la obra "Realidad Jurídica y Penal de Suramérica", explica que la violencia abarca una amplia variedad de fenómenos y manifestaciones; con múltiples formas, escenarios, víctimas y victimarios de la violencia, así como debates en torno a su complejidad, multicausalidad, corresponsabilidad y erradicación. Es entonces la 
violencia una acción intencional del uso de la fuerza o el poder, por la cual una o más personas producen daño físico, mental, psicológico, sexual o en su libertad de movimiento o muerte a otras personas, o a sí mismas, con un fin predeterminado que tiene tres componentes básicos: a) la intencionalidad del uso de la fuerza o poder; b) la generación de un daño; c) el fin perseguido, en el que subyace el ejercicio de alguna forma de poder, bien sea en el ámbito del hogar, del público o del grupo.

Dávila (2010), en el texto "La acción de la defensoría pública" manifiesta: "Las organizaciones criminales alcanzan su plena madurez cuando son capaces de realizar delitos impunemente y mantener un Estado de zozobra y preocupación constante en todos los niveles de la sociedad" (p. 37). La inseguridad en el país tanto pública y la inseguridad privada, afectan de una u otra manera e intensidad, la vida cotidiana en las ciudades y pueblos con cifras muy alarmantes.

Las sociedades latinoamericanas desde mediados del siglo pasado se han caracterizado por el incremento de la violencia y actividades delictivas destacándose entre los delitos menores como flagelos de la violencia que con mayor incidencia afecta a todos los estratos de la sociedad latinoamericana al punto que uno de cada cinco latinoamericanos cuyas edades oscilan entre 15 a 40 años ha sido víctima de diversos delitos.

Se debe destacar que el sistema judicial actual de una forma tradicional e histórica se manifiesta como ineficiente en la resolución de los delitos menores, a los cuales no presta la atención requerida y le resta importancia, considerándolos delitos de segunda categoría, como consecuencia de la saturación existente en el sistema judicial, es imposible dedicar suficientes esfuerzos y recursos a la resolución de una problemática que por su reincidencia destaca como un fenómeno cultural e histórico.

También debe tomarse en cuenta que la regulación legal existente en la actualidad que abarca los delitos menores se destaca por la tolerancia en sus decisiones las cuales se revelan como ineficaces, tales elementos han provocado una actitud en la sociedad que se traduce en desconfianza total en la resolución efectiva de los delitos sin lograrse una reparación integral de las víctimas, existiendo una insatisfacción social. 
En el Ecuador los delitos contra la propiedad y las personas son un fenómeno que se produce en contextos urbanos. Respecto a este punto es necesario considerar que, en cierta medida, se hace evidente que el problema de los delitos contra la propiedad y las personas, presentan características de un fenómeno que se acentúa en los estratos sociales menos favorecidos, los cuales son víctimas de las desigualdades sociales y de un sistema judicial incapaz de brindar una resolución eficaz y expedita.

Binder (2010), en el texto "El incumplimiento de las normas procesales", señala que la inseguridad ciudadana producto de la violencia y la criminalidad es un tema prioritario por ser este uno de los aspectos que más afecta la calidad de vida y el bienestar de la población. Es por esto que en el año 2009 fue creada la Secretaría General de Seguridad y Gobernabilidad en el Distrito Metropolitano de Quito, para implementar políticas de seguridad, prevención de la violencia e inseguridad ciudadana, asistencia técnica y fortalecimiento organizacional.

La violencia urbana en la provincia de Pichincha, en los últimos años ha adquirido un protagonismo espantoso en el escenario de las urbes tradicionalmente reconocidas como son Quito, Sangolquí, Cumbayá, Tumbaco y otras zonas aledañas; es urbana porque sucede dentro de la delimitación de las ciudades y área pobladas, tomando en cuenta el crecimiento demográfico de la provincia, en las ciudades aparecen como la cuna que engendra las peores patologías de la criminalidad ya que en los últimos años y meses se han visto alarmantes realidades sobre crímenes asaltos a personas con la respectiva consecuencia de muerte. Actualmente, la mayoría de la población de la provincia es urbana, esto ha generado un carácter violento por la desigualdad social, segregación espacial, lucha por la sobrevivencia en la pobreza, falta de planeación, ineptitud y autoritarismo de los poderes tanto políticos como económicos.

Pérez (2013), señala que se han incrementado los delitos y por consecuencia las causas a ser solventadas por un sistema judicial actualmente congestionado, situación que agrava las falencias dentro del sistema y profundiza la necesidad de aplicar herramientas legales que agilicen los procesos y permitan un mejor uso de recursos económicos y humanos. 
El incremento de las causas en hasta un 50\% según los datos aportados por el Sistema Nacional de Justicia, se debe en gran medida a la utilización de recursos legales que prolongan el proceso y que incurren en un gasto excesivo para el Estado en virtud de aportar los recursos necesarios para sufragar los sueldos de empleados públicos, centros penitenciarios, traslados, inmuebles, entre otros, los cuales han hecho del sistema judicial nacional una pesada carga a ser solventada por el erario público.

También es de señalar que los centros penitenciarios a nivel nacional poseen una sobrepoblación de hasta un $40 \%$ por encima de tales instalaciones según los últimos datos aportados por el Ministerio del Interior, como resultado del uso indiscriminado de medidas cautelares, situación que no favorece la descongestión del sistema de justicia, e incrementa los gastos del Estado para satisfacer las necesidades de una población carcelaria en incremento. Se evidencia también un bajo índice de resolución de conflictos legales alcanzando una eficiencia de un $40 \%$ en resolución de la totalidad de los casos ingresados como consecuencia de la utilización desmedida del método ordinario de resolución de conflictos.

Entre las causas que se destacan como factores de congestión del sistema judicial ecuatoriano se hace evidente la existencia de un sistema judicial que rechaza la utilización de medios alternativos para impartir justicia enfocándose solamente en los medios de justicia tradicionales, es decir llevando a cabo prácticas procesales ordinarias en materia penal. También se debe destacar que al mantenerse el sistema judicial en una situación en la que no se desarrolla, se ve afectada la correcta aplicación de la normativa legal existente.

Los elementos anteriormente expuestos entre los que se destaca la inutilización de prácticas procesales alternativas que permitan impartir justicia de forma expedita, efectiva y con el máximo ahorro de recursos humanos y materiales para el sistema judicial incurriendo en su lugar en la utilización de prácticas procesales ordinarias trae como consecuencia la insuficiente e inadecuada aplicación de la norma jurídica penal, así como la pérdida de credibilidad en el sistema legal.

Asimismo, al no aplicarse procesos de resolución de conflictos penales alternativos, se lleva a cabo un excesivo uso del procedimiento ordinario, único medio de impartir justicia conocido por los funcionarios y abogados en libre ejercicio de la profesión y defensores 
públicos, elementos que atentan contra la imprescindible actualización que deben asumir los profesionales del Derecho para garantizar la calidad y dinamización legal demandada.

\section{LA CONGESTIÓN JUDICIAL EN ECUADOR}

El sistema judicial ecuatoriano a pesar de ser uno de los más desarrollados de América del Sur, adolece de mecanismos judiciales alternativos que permitan impartir justicia de forma expedita, logrando un ahorro sustancial de recursos económicos y humanos de modo que el sistema judicial no se convierta en una carga económica para el Estado.

Cabezas (2012), explica que la reiteración en la utilización de métodos ordinarios para impartir justicia se revela como la causa fundamental de la prolongación desmedida de los procesos judiciales, así como los elevados costes económicos tanto para el Estado como para particulares. Además, debe señalarse que como consecuencia de la lentitud en la resolución de conflictos judiciales se hace un sobre uso de medidas cautelares, situación que se traduce en el incremento de la población penitenciaria y por ende en mayores gastos materiales y humanos para el sistema judicial penal.

La inaceptación y resistencia ante la puesta en marcha de mecanismos alternativos para agilizar la resolución de conflictos judiciales por parte de los abogados en libre ejercicio de la profesión, defensores públicos y servidores públicos constituyen el principal escollo a ser superado para lograr implementar tales mecanismos de resolución de conflictos judiciales.

También debe tomarse en cuenta la inexistencia de programas de capacitación periódicos dirigidos a abogados en libre ejercicio de la profesión, defensores públicos y funcionarios públicos del sistema judicial penal en los que se propicie el conocimiento y desarrollo de habilidades, concernientes a mecanismos de resolución de conflictos judiciales de forma abreviada y con una utilización óptima de los recursos materiales y humanos a disposición del sistema judicial penal.

La falta de capacitación a los actores del sistema judicial, tomando en consideración que no solo son los jueces y magistrados los que juegan un papel preponderante, sino que deben constar los abogados como 
litigantes y promotores hacia una justicia transparente, esto implica que no deben existir sesgo judicial.

Demostrando imparcialidad, sin embargo, se tiene una alta carga de complejidad en la decisión al valorar a la víctima y al infractor, toda vez que los dos son seres humanos, cada uno ubicado desde su posición, además de una clara identificación de discriminación de las víctimas ante el sistema social y judicial, ya sea debido a su nacionalidad, etnia, condición social, afinidad política, religiosa.

La insuficiente capacitación y conocimientos desde el punto de vista judicial de los funcionarios, la parcialidad de los jueces, así como la falta de decisión legal efectiva que afecte tanto a la víctima y al infractor, lo cual provoca una deficiente aplicación de las normas legales en los procesos judiciales, situación que se traduce en la insatisfacción de las víctimas por las decisiones legales tomadas, elementos que provocan una falta de credibilidad en la justicia e incremento de la impunidad por lo que se multiplican los hechos delictivos.

Tales elementos provocan una pérdida de credibilidad en un sistema que debe ser igualitario para todos sus ciudadanos recalcándose el descontento social por la actitud de ciertas autoridades policiales y legales las cuales facilitan y agilizan las medidas de protección hacia las víctimas. Asimismo, son de destacar los vicios y deficiencias que aún persisten en el sistema judicial, lo que proporciona una imagen negativa del mismo a la opinión pública lo cual provoca falta de credibilidad y debilitamiento institucional.

\section{RAZONES ATRIBUIBLES A LAS OTRAS RAMAS DEL PODER PÚBLICO}

El incremento y desarrollo de las organizaciones delictivas que actúan tanto a nivel nacional como internacional es una problemática actual que ha traído como consecuencia que actividades ilícitas tales como el narcotráfico, prostitución, tráfico de armas y trata de personas, hayan encontrado en los países latinoamericanos el espacio que les permite transformar sus ingresos ilícitos en dinero legalmente reconocido ante las leyes y la sociedad.

García (2011), señala que otra de las causas que hacen de las Economías latinoamericanas blancos fáciles del crimen organizado para 
transformar sus ingresos ilícitos en lícitos son las facilidades de inversión de las Economías latinoamericanas generalmente subdesarrolladas, las cuales buscan inversionistas que permitan desplegar su comercio y progreso económico. Son de señalar que la existencia de legislaciones deficientes, vetustas y en muchos casos sin actualizaciones que se ajusten a las expectativas y necesidades de la justicia actual facilita la acción de profesionales inescrupulosos que brindan sus servicios al crimen organizado transformando el dinero proveniente de sus delitos en dinero lícito.

\subsection{Causas de congestión atribuibles a la administración de justicia}

En virtud de lo expuesto en los párrafos anteriores, encontramos que la referida congestión en la administración de justicia obedece a que, a pesar de estar contemplada en la Constitución Política en el contexto de Derechos tanto para los ecuatorianos, así como para los extranjeros residentes o transeúntes en el país, y debido al poco tiempo transcurrido de su promulgación de las normas aplicables, además del poco interés de los actores hacia su conocimiento, debido a la poca cultura de los participantes del sistema en cuanto a mantener actualizado su conocimiento, no hacen uso de medios alternativos judiciales abreviados.

Gaviria (2010), explica que las antiguas formas de aplicar la norma jurídica, por aún contar con un sistema judicial viciado con prácticas procesales en materia penal tradicionales, en las que han primado oscuros y alarmantes niveles de corrupción en la aplicación de la normativa en el sistema, además de la lentitud de la administración de justicia, al saber que una justicia que llega tarde ha dejado de ser justicia, y son muchos los casos de víctimas que han dejado a la justicia divina su reparación desconfiando por sobre manera de la justicia como una institución creíble.

Tal situación se traduce en la vulneración de los Derechos de las víctimas en especial las de homicidio, produciéndose constantes violaciones de los Derechos humanos que dejan entrever un sistema judicial ineficiente, el cual no suple las necesidades de los ciudadanos y ciudadanas ecuatorianos, pues los mecanismos de reparación integral del delito de homicidio son ineficaces, así como la protección a las víctimas de tal hecho punible. 
En la actualidad persisten los procesos prolongados, en los que la administración de justicia se imparte con extrema lentitud, situación debida en gran medida a la sobrecarga de trabajo, así como estructuras anacrónicas del sistema judicial, siendo la desactualización en normas jurídicas recientes por parte de los funcionarios de dicha institución es uno de los elementos que tiende a dilatar los procesos.

Tal situación se traduce en el represamiento de causas, situación que influye negativamente en la institucionalidad de la función judicial disminuyendo notablemente la efectividad de tal órgano legal, por lo que actualmente impera un descontento social hacia la estructura y funcionamiento del sistema judicial ecuatoriano.

\subsection{Los litigantes como causantes de la congestión}

La utilización de resolución de conflictos judiciales en Ecuador, se dirige básicamente a procesos ordinarios en los que no se aplica ninguna herramienta legal alternativa que propicie una resolución rápida y efectiva de los conflictos, es frecuente que los litigantes empleen prolongados períodos en la resolución de tales hechos.

Cabe destacar la tendencia a prolongar los procesos judiciales por parte de los litigantes, como elemento que garantiza una mayor ganancia económica en detrimento de los intereses de las partes en conflicto y del sistema judicial, el cual debe destinar amplios recursos humanos y materiales para solventar dichos procesos.

Tales circunstancias atentan contra la resolución rápida y efectiva de los procesos judiciales evidenciándose una amplia variedad de casos sin resolución, situación que afecta la credibilidad en el sistema judicial ecuatoriano y su capacidad de brindar una justicia expedita, equitativa y accesible a todos los ciudadanos.

\subsection{Congestión en la jurisdicción ordinaria}

La realidad social actual del Ecuador, con su desarrollo, ha generado nuevas conductas delictivas que han invadido todos los espacios sociales y que ya no distinguen a sus víctimas si son mayores, ancianos, o niños. Los objetivos de la violencia cada vez hacen menos diferencias, lo que posiblemente la vuelva más cruel que antes. 
Los costos sociales, psicológicos, morales y económicos de la violencia son incalculables, existen daños materiales que podrían ser sujeto de cálculo, pero existen infinitos daños morales que pertenecen a la subjetividad y que rebasan toda posibilidad de medición. América Latina a partir de la década del 60 del siglo pasado se transformó en forma gradual en un terreno fértil para bandas delictivas, grupos o asociaciones criminales como consecuencia de un conjunto de factores económicos, políticos y sociales que lesionaron la institución familiar, el respeto a la ley y como consecuencia transformaron las sociedades en ambientes violentos, la pobreza fue la génesis de la marginalidad y delincuencia, apareciendo en muchos países latinoamericanos el robo agravado, acción que en el pasado solo era atribuible a piratas y salteadores de caminos.

Larrea (2011), señala que no es posible medir los costos de la inseguridad únicamente desde una perspectiva monetaria pues existen otras que no pasan por ese orden sino por el de las subjetividades que no tienen valor como, por ejemplo: la muerte del papá, proveedor doméstico y social, o la muerte de un niño cuya desaparición producirá heridas que desordenarán la vida de todos los miembros de su familia.

Ante el conflicto del tema, es necesario un modelo de control social que se base en los principios democráticos y en el respeto a los Derechos, modelos alternativos que den la cara al problema de manera directa y que, al mismo tiempo, creen estrategias destinadas a mejorar las condiciones de vida de los desfavorecidos, modelos plurales que enfrenten las desigualdades sociales, causas primarias de los desórdenes y las violencias. Entre las múltiples preocupaciones ciudadanas, la violencia constituye quizás la más importante.

De hecho, las investigaciones de opinión que se realizan a diario en las pequeñas y grandes ciudades dan cuenta de un creciente temor que invade a la población de todas las condiciones, aúnque sea más evidente en los estratos populares, los homicidios, robos, asaltos y muchas otras formas de agresión forman parte de la vida cotidiana.

El equilibrio psicológico de la persona depende en gran medida del núcleo familiar en el que se desenvuelve y el entorno social aúnque no debe obviarse el elemento genético hereditario que si bien no es definitorio crea una predisposición en el individuo, por lo que se puede constatar que aquellos individuos que se desarrollan en ambientes delictivos, violentos y son hijos de infractores poseen una amplia po- 
sibilidad de cometer crímenes, mientras que aquellos individuos que se desenvuelven en un ambiente familiar y social sano incluso si son hijos de infractores presentan pocas posibilidades de delinquir.

Spino (2011), explica que la violencia intrafamiliar se ha incrementado en las últimas décadas como consecuencia de un conjunto de factores entre los que destaca la migración, la liberación sexual de la mujer, la lucha por los Derechos e igualdad de la mujer, entre otros elementos que han acrecentado las actitudes machistas y discriminatorias; también debe destacarse el factor cultural, el cual refuerza el pensamiento e idea de la superioridad del hombre sobre la mujer en todos los sentidos.

Cada día la mujer ecuatoriana gana mayores espacios en la productividad, Economía y ciencia del Ecuador no existiendo una actitud acorde por parte de la sociedad en general ante la emancipación de la mujer, la cual es reconocida desde el punto de vista económico, productivo y científico, pero se le relega a un segundo plano dentro de la familia limitando su accionar solamente a la crianza de los hijos y mantenimiento del hogar.

\subsection{Congestión penal}

El sistema penal se revela como el mecanismo de control social capaz de regular las actividades y manifestaciones sociales observando la legalidad existente y garantizando la accesibilidad de todos los ciudadanos a una justicia efectiva y expedita que aborde de forma igualitaria los Derechos y necesidades de sus ciudadanos.

Es de destacar que el sistema penal ecuatoriano adolece de recursos y personal en cantidades suficientes para lograr una resolución efectiva y expedita de los conflictos penales, haciendo uso solamente de recursos legales ordinarios caracterizado por su lentitud.

La inutilización de herramientas legales alternativas dentro del sistema penal ecuatoriano prolonga la resolución de conflictos y exigen una mayor utilización de recursos humanos y materiales.

Es de destacar que en el año 2014 ingresaron 135.340 casos al sistema judicial penal ecuatoriano, de los cuales el $20 \%$ fue solucionado de forma expedita a través de los medios ordinarios de justicia, evi- 
denciándose una congestión de un $80 \%$ de los casos, en la mayoría se aplicaron medidas cautelares como la prisión preventiva.

De acuerdo con la información entregada por la Corte Nacional de Justicia en su informe de rendición de cuentas del año 2016, en el año 2015 ingresaron 294.480 casos penales, de los cuales el $25 \%$ se solucionaron mediante el uso de métodos ordinarios de justicia, persistiendo una congestión de un $75 \%$, situación que se agrava en el año 2016 con 354.818 casos, de los cuales solo el 23\% fue solucionado por el uso de los métodos ordinarios de justicia, observándose un $77 \%$ de congestión en el sistema judicial penal ecuatoriano.

Tal situación revela las falencias del sistema judicial ecuatoriano al no hacerse uso de métodos alternativos de justicia que incidan positivamente en la descongestión del sistema y eleven la calidad del mismo posibilitando una justicia efectiva, eficaz y expedita con la utilización óptima de los recursos materiales y humanos a disposición del sistema judicial penal.

\subsection{El procedimiento abreviado}

Binder (2010), explica que el procedimiento abreviado que contempla el Código Orgánico Integral Penal, tiene su origen en varias legislaciones latinoamericanas que se ha visto en la necesidad de incorporar nuevas alternativas para la solución de los conflictos penales. Estas legislaciones han buscado adoptar un sistema distinto al tradicional inquisitivo, y han encontrado en el sistema oral, una alternativa para dar un nuevo tratamiento criminal a las causas.

El sistema oral tiene su mayor representación en el sistema penal norteamericano, el mismo que ha sido considerado por los legisladores de varios países como un modelo a seguir, tomando en cuenta la rapidez con la que culminan los procesos penales con mejores resultados que el sistema anterior respecto de las víctimas y por el ahorro de recursos que ello podría generar. A pesar de lo dicho, no es posible adaptar todo un sistema penal a una realidad distinta de la que fue su inspiración, y es por ello que los asambleístas han incorporado al cuerpo procesal penal solo ciertas instituciones, con algunas variantes, para que operen en la realidad ecuatoriana y dentro de estas instituciones se encuentra el procedimiento abreviado que es, una nueva alternativa para procesar ciertos delitos. 
El Procedimiento Abreviado, procedimiento especial incorporado a la legislación por intermedio del Código de Procedimiento Penal publicado en el Registro Oficial No. 360 del 13 de enero del 2000, el cual entro en vigencia a partir de julio del año 2001, generó muchas inquietudes por parte de los funcionarios judiciales, abogados y en general por todos los que de alguna forma estaban inmiscuidos en algún proceso penal; así mismo recibió comentarios positivos y negativos no solo de tratadistas nacionales sino de extranjeros. No se cuestionaba el Procedimiento Abreviado como tal, sino las reglas y requisitos para su aplicación y todas las consecuencias jurídicas que conlleva.

En el país a diferencia de otros países, el Procedimiento Abreviado, a pesar de ser una innovación positiva, el caduco sistema procesal penal, sigue siendo un procedimiento poco aplicado en el país ya sea por desconocimiento, desinterés o por una cultura de conflicto. A diferencia de otros países de Latinoamérica en los cuales este procedimiento casi ha desplazado a los tradicionales sobre todo cuando se trata de resolver asuntos o delitos que no representan una amenaza o no son tan graves para la sociedad, en el país no ha tenido la acogida que se esperaba.

Con la incorporación del Procedimiento Abreviado han surgido varias dudas que pueden originar algunas controversias y podrían llevar a dudar de su eficacia; ha recibido varias críticas, pero también argumentos a favor, por lo tanto, se hace necesario aclarar algunos puntos referentes a su aplicación, señalar ciertas dudas, pero sobre todo realizar observaciones respecto al trámite y a los efectos procesales que emanan de su aplicación.

En la búsqueda constante de tratar de mejorar el sistema procesal penal ecuatoriano, el procedimiento abreviado aparece como una tabla de salvación al ser una herramienta incorporada para simplificar el proceso penal. El sistema de justicia ecuatoriano podrá valerse de esta herramienta para dotar de mayor agilidad y una dinamización del sistema y evitar que cada día se sigan acumulando causas.

Guerrero (2011), señala que el respeto a la justicia, el fortalecimiento los Derechos del procesado, la simplificación del proceso penal y la exclusión de formas de justicia que obstaculizan el flujo de casos, son los principales objetivos que se buscaron con las últimas reformas encaminadas a solucionar los graves problemas del sistema actual. 
La celeridad del proceso y la oralidad son principios que se plasmaron en las reformas ya que las nuevas instituciones están orientadas a simplificar el proceso y de alguna forma evitar la acumulación de causas en los juzgados y liberar a los jueces de la dura tarea de sustanciarlo todo y más bien simplifican su labor, los fiscales les dan elementos objetivos y claros para que puedan decidir de manera imparcial.

El Procedimiento Abreviado nace como un mecanismo que da soluciones rápidas y efectivas bajo ciertas circunstancias especiales y tomando en cuenta parámetros para su aplicación. Dicha figura ha sido incorporada en otras legislaciones en Latinoamérica y la experiencia en estos países servirá de punto de partida para enfocar sus ventajas y desventajas.

El actual sistema procesal penal señala los procedimientos denominados como especiales dentro de los cuales se encuentra incorporado el Procedimiento Abreviado. Realizando un análisis de lo que se denomina como procedimientos especiales, la legislación los califica como tales en virtud que son formas particulares de solución de los conflictos penales que cumplen circunstancias especiales para entrar a formar parte de lo que se denomina procedimiento especial.

Gaviria (2010), señala que la doctrina da el carácter de ordinario o especial al procedimiento tomando en cuenta el mayor o menor tiempo con el que se resuelven los casos, pero obviamente tomando en cuenta la especialidad de los casos y los requisitos para que sean considerados como ordinarios o especiales. Los casos que por su naturaleza deben seguir con actos procesales comunes para todos los juicios, se denominarán ordinarios; $y$, aquellos que reúnan ciertos requisitos del Procedimiento Abreviado. Realizando un análisis de lo que se denomina como procedimientos especiales, la legislación los califica como tales en virtud que son formas particulares de solución de los conflictos penales que cumplen circunstancias especiales para entrar a formar parte de lo que se denomina procedimiento especial.

La efectividad, utilidad y actualidad del procedimiento abreviado es manifiesta en el sistema de justicia norteamericano, el cual a pesar de verse sensiblemente afectado por el incremento de la delincuencia logra mantener de forma plena su funcionabilidad y efectividad debido al uso cotidiano del procedimiento abreviado el cual garantiza la descongestión judicial lográndose un acuerdo con el imputado sin necesidad de probar el delito o culpabilidad del mismo a cambio de la 
confesión de la culpabilidad, acción que se traduce en la disminución de la pena o cargos imputados al mismo.

A manera de compendio, si el patrimonio político de la colectividad se mantiene y protege a través del conjunto de normas jurídico-penales que describen y sancionan determinadas conductas, el aspecto constitutivo del procedimiento abreviado se manifiesta en la normatividad de lo justo y la especificación de lo antijurídico, respecto de la valoración de los intereses fundamentales de la colectividad.

\subsection{Características}

Cabezas, (2012), manifiesta que en esta clase de procedimientos concurren ciertas particularidades que en definitiva son las que tienden a caracterizarlo y distinguirlo de los demás de su especie. Es característico el aspecto temporal por ejemplo, cuya utilidad surge de la correspondencia entre el medio empleado (procedimiento abreviado) y el fin perseguido (celeridad en la resolución de los conflictos sociales); toda vez que la abreviación se proyecta como un medio de auxilio a quienes son víctimas de los agravios delictivos y como medio para mejorar el procesamiento de los culpables, a través de convenios o negociaciones que canalizados según fórmula se traducen como ejercicio eficaz de la justicia penal.

Para viabilizar el procedimiento abreviado se requiere el acuerdo entre el fiscal y el procesado acompañado de su defensor. De ello se desprende que, se trata de un procedimiento que procura la solución consensuada del conflicto sin vulnerar el principio de la verdad histórica ni la pretensión punitiva de la sociedad.

Gutiérrez (2011), explica que de otro lado, entendidas como son las penas privativas de la libertad el eje del sistema penológico, ocurre que el procedimiento abreviado regula todas las causas penales por delitos cuyas penas desde un punto de vista promedial no sean superiores a las de prisión (para el caso de prisión cuyo máximo es de cinco años) o como en otras legislaciones para penas no privativas de libertad, tal el caso, las sanciones económicas o multas simplemente. Más, lo que si queda claro es que el procedimiento abreviado no opera para delitos sancionados con penas de reclusión. 
Ahora y en cuanto al marco jurídico regulador de la escala punitiva, el procedimiento abreviado procura acordar un punto entre el mínimo y el máximo de la escala penal conminada para el delito imputado (o la elección de una pena entre las previstas como alternativas) que a criterio del acusado le resulte favorable, como contrapartida de su consentimiento al procedimiento más rápido y económico o de su reconocimiento o aceptación de los hechos que se le atribuyen: la confesión ha sido valorada tradicionalmente como una circunstancia atenuante de la pena.

Se trata además de un procedimiento que intenta aligerar el proceso penal evitando que se practiquen ciertas fases que se tornan inútiles y evitando asimismo la repetición de ciertas actuaciones que ya se hayan realizado. Obsérvese y esto a manera de ejemplo que en este procedimiento: se concentran ciertas etapas del procedimiento ordinario, se dan facilidades a las partes ya para la conformidad sobre la aplicación del procedimiento o ya para la negociación de la pena, se da posibilidad al juez o al tribunal penal según corresponda para que dicte sentencia según circunstancias de este procedimiento y según pruebas alejadas de las exigencias del ordinario, en cuanto a la prueba tiene prelación la confesión del procesado aúnque no es la única que se practica y observa para dictar sentencia, en algunas legislaciones no en todas pese a existir sentencia condenatoria se procura la irrecurribilidad de la misma, se practican diligencias sin demora o en plazos reducidos, si no se las exige de modo inmediato pero siempre con observancia de las garantías del debido proceso.

Pese a la independencia de su intervención en otras actuaciones procesales, es característico y hasta de cierto modo requisito si ne qua non la participación del fiscal, recuérdese, que según las circunstancias de procedencia, según la organización del trámite e inclusive según la propia validez del procedimiento se exige la actuación de este representante de la fiscalía.

El interés por haber incorporado este procedimiento a la legislación penal se basa en la descongestión de los procesos penales y sobre todo en la necesidad de simplificar los procedimientos, vinculándose directamente al proceso de modernización de la justicia en el mundo. Perretti (2010), señala que debe identificarse el delito cometido y por ende la pena a imponerse, este procedimiento opera en los casos en que la pena a imponerse no exceda de cinco años, es decir delitos considerados como leves, los cuales por su naturaleza no representan ma- 
yor alarma para la sociedad. Si un hecho punible reúne este primer requisito el procesado puede optar por acogerse a este procedimiento, es en este momento donde el elemento consensual cobra vital importancia ya que debe existir un acuerdo entre el fiscal y el procesado, que en la legislación debe manifestarse por escrito; si no hay este acuerdo no puede optarse por este procedimiento.

Con este acuerdo se asume que hay conformidad de las partes para optar por la abreviación. Lo que queda claro es que este procedimiento no es admisible para los delitos cuya pena supere los 10 años. El procedimiento abreviado le permite al fiscal como al procesado negociar sobre la pena a imponerse tomando en cuenta el máximo y el mínimo en la escala penal para el delito imputado (o la elección de una pena alternativa) que a criterio del procesado le resulte favorable. El hecho que el procesado acepte declararse culpable y reconozca como verdaderos los resultados de la investigación, le favorece en el sentido que la pena a imponerse será menor a la que se le pretendía imponer antes de optar por este procedimiento.

La omisión de ciertas etapas dentro del juicio, es característica de la brevedad penal, ya que la negociación de la pena le da la facultad al juez para dictar sentencia en una sola audiencia. Las participaciones del fiscal y del abogado son importantes porque son los sujetos procesales de los cuales emana el acuerdo. El fiscal presenta las pruebas emanadas de la investigación realizada y señala la pena que solicitará, luego, el procesado acepta acogerse a este procedimiento, consentimiento que es acreditado por el abogado defensor con su firma y se supone que informa a su cliente de las ventajas y desventajas del mismo. La pena a imponerse por parte del juez o tribunal penal no podrá ser mayor a la solicitada por el fiscal.

\subsection{Objetivo y finalidad}

El objetivo del procedimiento abreviado se puede resumir en lograr una mayor dinamización y eficiencia de la función pública, traducida en una administración expedita de justicia a través de la resolución inmediata de los cargos presentados al acusado, mediando un acuerdo en el cual el Fiscal logra que el acusado confiese su culpabilidad a cambio de una sanción menor a la que recibiría de ser juzgado a través del proceso ordinario. 
Lombardía (2012), señala que el mayor beneficio es la disminución de la carga de trabajo fiscales y jueces y donde los particulares podían sentirse satisfechos de mejor manera al ser resarcidos en el daño causado, dejando de lado un proceso penal que a muchos no interesa o si les interesa no tienen la voluntad y la constancia para continuarlo.

El aporte de este nuevo procedimiento, entonces, solo se podrá medir sin tomar en cuenta delitos que tienen la característica de ser muy numerosos y, por consiguiente, no se verá un resultado positivo o negativo sino cuando el tiempo transcurra, se entiendan sus beneficios y se contribuya con capacitación e infraestructura a esta nueva alternativa para procesar esta clase de delitos.

Tal y como queda expuesto en la cita anterior la esencia del procedimiento abreviado está dada por lograr una mejor funcionabilidad del sistema de justicia y un uso adecuado de los limitados recursos humanos y materiales que poseen, lográndose administrar justicia de forma expedita y obteniendo resultados satisfactorios comparables a los procedimientos judiciales ordinarios.

Ferrajoli (2011), afirma que el procedimiento abreviado es una nueva herramienta procesal para perseguir los delitos considerados de menor gravedad, que, manejado de buena manera por los actores de la vida judicial, puede llegar a ser la institución procesal con la que se resuelvan la mayor cantidad de casos por estos delitos y, en el futuro, pueda servir para juzgar incluso delitos de mayor gravedad.

El éxito de este procedimiento puede traer muchos beneficios, como son: descongestionar la gran cantidad de procesos que se encuentran en manos de jueces y fiscales; agilitar las causas por delitos considerados graves y, sobre todo, concientizar a la población de su deber de asumir su responsabilidad cuando cometan un delito.

Se evidencia que el procedimiento abreviado además de garantizar la descongestión judicial e incrementar la eficiencia y calidad de la función judicial, garantiza el pleno cumplimiento de los Derechos humanos lográndose un procedimiento judicial, el cual puede ser resuelto de forma inmediata disminuyendo de esta forma el período de condena del acusado y por ende los daños psicológicos que del mismo puedan desprenderse. 


\subsection{La admisibilidad del sometimiento al procedimiento abreviado}

Los requisitos para la admisibilidad del procedimiento abreviado son:

Una vez que se ha conocido la naturaleza jurídica del procedimiento abreviado, es necesario analizar la practicidad de este procedimiento para poder incorporar nuevas ideas que permitan un buen manejo de su admisibilidad. El Artículo 635 del COIP manifiesta que el procedimiento abreviado debe sustanciarse de conformidad con las siguientes reglas, aquellas infracciones cuya pena máxima privativa de libertad no sobrepase los 10 años, son susceptibles al procedimiento abreviado, es imprescindible que la propuesta del fiscal se presente desde la audiencia de formulación de cargos hasta la audiencia de evaluación y preparatoria de juicio, verificándose el consentimiento del procesado a la aplicación del procedimiento abreviado, garantizándose la inviolabilidad de sus Derechos constitucionales, tomándose en cuenta que la existencia de varias personas procesadas no es un elemento limitante para la aplicación del procedimiento abreviado, finalmente es de destacar que la pena a aplicar en ningún caso podrá ser superior a la sugerida por el Fiscal.

Este artículo establece las condiciones o requisitos para que el procedimiento abreviado sea admitido a trámite, pero estos a su vez, se encuentran supeditados a la etapa en la que se encuentre el procedimiento ordinario. La norma establece que tal sometimiento podrá ser admitido siempre que sea planteado hasta la audiencia de evaluación y preparatoria de juicio.

A primera vista, se puede interpretar como que el sometimiento al procedimiento abreviado se puede realizar hasta antes que el juez de Garantías Penales dicte sentencia. Se puede concluir en primer lugar, que el sometimiento al procedimiento abreviado se puede proponer desde que el Fiscal tiene conocimiento del delito, incluso antes que dicte la resolución dando inicio a la etapa de instrucción, pues, el procesado puede admitir que ha cometido el delito, antes que se dicte tal resolución; por consiguiente, el Fiscal solicitará tal sometimiento en la misma resolución de apertura a la etapa de instrucción; y luego, este sometimiento al procedimiento abreviado, se puede proponer también en la audiencia de evaluación y preparatoria de juicio. 


\subsection{Ventajas del procedimiento abreviado}

- El procedimiento abreviado permite a la Fiscalía concentrar sus esfuerzos en los casos más graves y difíciles, al tiempo que los jueces de Garantías Penales tendrán mejores oportunidades para fijar, conocer y fallar los juicios.

- El conocimiento y fallo oportuno de casos implica una importante reducción del número de presos sin condena, es decir, evita que las largas esperas para la realización del juicio estando en prisión, conviertan al encierro preventivo en verdadera condena anticipada.

- La eliminación de la incertidumbre respecto de la suerte de un imputado constituye tanto para este como para la víctima, la satisfacción del Derecho a una justicia pronta y cumplida.

- Respecto de la pena, le permite al procesado conocer anticipadamente que no será condenado a una pena mayor que lo acordado, pues este acuerdo producto de la confesión conlleva a obtener una reducción de la pena dentro de los límites de la escala penal conminada para el delito que se imputa.

- Asimismo, los procesados, privados de la libertad, al obtener una pronta condena inician su tratamiento penitenciario, lo que les permite lograr más rápidamente los beneficios que establece la ley.

- El procedimiento abreviado además conlleva una más racional distribución de los recursos afectados por el Estado al proceso penal.

- Agiliza los procesos penales y evita dilaciones indebidas en los mismos, lo que deviene en una aceleración de las condenas.

- El abaratamiento de costos, así como la disminución de recursos humanos es otra de las ventajas que con la abreviación de procesos se persigue.

- Alivia la situación de juzgados y tribunales, esto es, se los descongestiona de saturadas causas por resolver.

Adicionalmente, el procesado debe mirar otras ventajas de someterse al procedimiento abreviado, tales como el ahorro de tiempo para recibir una sentencia, frente a la inconveniencia de un proceso largo 
y tortuoso en el que el procesado se encuentra en una situación de incertidumbre y donde el daño psicológico puede ser muy grave, pues, tendría que acudir a las audiencias y en la etapa del juicio confrontar testigos y documentos que buscan probar su culpabilidad.

Muy importante también, dentro del aspecto económico, es la ventaja que el procesado no tendría que gastar en honorarios de abogados y peritos, pues, no se puede desconocer la preferencia que tienen las personas de defenderse con un abogado particular y no esperar un defensor público, precisamente porque no existe confianza en una correcta y responsable asesoría dentro del juicio.

Al mirar todas las posibles ventajas y desventajas de asumir la responsabilidad por el delito cometido, se deben establecer reglas claras y precisas para el correcto desenvolvimiento de este procedimiento, así también, es muy importante que se establezca una normativa dirigida a una correcta negociación por parte de los fiscales, para que ahí se determine, en razón de la pena que corresponda a cada delito, un porcentaje de rebaja.

En el Código Adjetivo Penal que estuvo vigente, únicamente se establecía este beneficio para el caso que el procesado admitiera la comisión del delito, a diferencia de otras legislaciones como la de Estados Unidos, en la que el beneficio se otorga también por información adicional, por rendir testimonio en juicio, aportar nuevas pruebas u otros autores en el hecho delictivo; estos motivos de negociación, no están contemplados en la legislación ecuatoriana podrían servir en procesos en los que la investigación es muy difícil de realizar y en verdad no existan indicios plenos sobre los autores del delito y todas las circunstancias que rodearon su cometimiento.

\subsection{Prerrogativas en la aplicación del procedimiento abreviado}

La legislación ecuatoriana nada dice sobre la forma como se debe realizar la admisión de los hechos por parte del procesado que desea someterse al procedimiento abreviado y las consecuencias de la misma. La admisión de culpabilidad tiene que darse libre y voluntariamente por parte del procesado y con el debido asesoramiento del abogado defensor público o privado. 
$\mathrm{Al}$ admitir el procesado el hecho que se le atribuye y, por tanto, las consecuencias del mismo, implica que este, de cierta forma, renuncia al ejercicio del Derecho de defensa y a la presunción de inocencia que tiene toda persona mientras no exista sentencia que declare lo contrario, consagrados en la Constitución de la República del Ecuador. En caso que el Juzgador no acepte o rechace el acuerdo, este no podrá ser prueba dentro procedimiento ordinario.

Ecuador es un Estado personalista fundado en el respeto de la dignidad humana. La Constitución de la República reconoce la primacía de los Derechos inalienables del ser humano. Se ha de proteger, entonces, el Derecho a la vida, esto es, que la persona exista, además de garantizar cierta calidad de subsistencia. La persona es el sujeto, la razón de ser y fin último del poder político por lo que se constituye en algo inalterable en el ejercicio del poder y su relación con la sociedad. Es a partir del respeto por la vida humana que adquiere sentido el desarrollo de la comunidad y el funcionamiento del Estado.

Binder (2010), señala que el proceso penal por sí mismo acarrea un grave perjuicio para el honor del procesado, por sus efectos estigmatizantes y es por eso que mediante esta garantía se reconoce el Derecho de la persona que ha sido sujeto de una persecución, de ser considerado y tratado como inocente por el ordenamiento jurídico en su conjunto hasta que no exista un pronunciamiento judicial firme en el sentido que el sujeto ha realizado un comportamiento delictivo.

Ya de inicio debe advertirse que el Derecho a la presunción de inocen $\neg$ cia no solo es una garantía que impone la consideración del procesado como inocente, sino que su efecto más importante radica en que exige que la persona que viene afrontando un procedimiento judicial sea tratada, en los diversos sectores del ordenamiento jurídico y la vida social, como una persona de la que aún no se ha comprobado responsabilidad alguna.

En el nuevo cuerpo procesal penal, se deja, en forma expresa, la posibilidad de no ejercer este Derecho e incluso de renunciar al mismo a través de la admisión de los hechos que se le imputan a la persona procesada. La presunción de inocencia, garantizada por la Constitución, puede terminar cuando el procesado realice la admisión de los hechos, pues, desde ese momento es él mismo quien se coloca en situación de culpable antes de dictarse sentencia, sin embargo, que en la sociedad esta presunción está bastante desgastada. 
La primera fuente de la institución jurídica del debido proceso se encuentra en los convenios y tratados internacionales, las normas constitucionales. En el Estado ecuatoriano, la actual Constitución de la República del 2008 promulga un Estado Garantista, en tal virtud la persona que considere que se han vulnerado alguno de sus Derechos o bienes jurídicos, por parte de otra persona natural o jurídica, tiene la facultad legal de acudir a los Juzgados o Tribunales Jurisdiccionales en demanda de justicia observándose el fuero legal, en razón del territorio, las cosas, las personas y de los grados.

El Ecuador al asegurar la vigencia de los Derechos Humanos y el respeto de las libertades fundamentales de mujeres y hombres, garantiza la vigencia del sistema democrático y la administración pública libre de corrupción, asegura la aplicación de principios como el de inocencia, Derecho a la defensa, entre tantos otros; tal es así que el artículo 75 de la Constitución de la República expresa que toda persona tiene Derecho al acceso gratuito a la justicia y a la tutela efectiva, imparcial y expedita; el Art. 76, señala que en todo proceso en que se determinen procesos y obligaciones de cualquier orden, se asegurará el Derecho al debido proceso que incluirá las siguientes garantías básicas; Art. 76 numeral 1. manifiesta que corresponde "a toda autoridad administrativa o judicial, garantizar el cumplimiento de las normas o Derechos de las partes"; en el numeral 2. del mismo artículo se refiere a la presunción de inocencia; 3. principio de ilegalidad; 4 . principio de eficacia probatoria; 5 . indubio pro reo; 6 . principio de proporcionalidad.

La admisión de los hechos por parte del procesado es, entre otras, una condición para que el Juez admita el sometimiento al procedimiento abreviado, por lo tanto, existe la posibilidad que este no sea admitido y es entonces cuando surge el problema de saber si esta renuncia (a defenderse y a que se presuma su inocencia) es permanente o deja de surtir efecto cuando el Juez no acepta el sometimiento al procedimiento abreviado.

Considero que este requisito responde a la necesidad de garantizar que el procesado, el momento de admitir el delito y de consentir en someterse al procedimiento abreviado, debe estar debidamente asesorado por su abogado defensor sobre las consecuencias de estos hechos y que no exista ningún tipo de presión por parte de terceros interesados, presión que puede producirse incluso por parte del Fiscal. 
Entonces, la responsabilidad de acreditar la libertad con la que el procesado decidió someterse al procedimiento abreviado recae sobre el abogado defensor, entendiéndose que tal responsabilidad abarca un correcto asesoramiento y comprobar que el consentimiento fue libre y voluntario, sin embargo, puede suceder que el abogado defensor sea quien ejerza algún tipo de presión con el fin de dar por terminado su trabajo en la defensa de la causa.

Esta es una muy buena opción, pues, de acuerdo con lo que dice la norma, la sola firma del abogado defensor sirve para demostrar que se han cumplido con la asesoría al procesado, que este ha tenido la libertad para decidir y lo ha hecho en forma voluntaria, con lo que el abogado solo está sujeto a lo que se manifiesta en la Ley de Federación de Abogados respecto del asesoramiento profesional y a las sanciones que allí se establecen por su incumplimiento; mientras que, bajo la modalidad sugerida por el autor, el abogado defensor que hace una declaración juramentada sobre el cumplimiento de estos requisitos se coloca en una situación de mayor responsabilidad, pues, en caso que su declaración no esté ceñida a la verdad se involucraría en el cometimiento de un delito.

Asimismo, para que esta modalidad opere de buena manera, se debe evitar que, por el contrario, sea el procesado quien abuse de esta, ya que puede responsabilizar al abogado defensor de su situación argumentando una posible defensa; por esta razón, la acreditación la deben hacer en conjunto el procesado y el abogado defensor, y cuando el procesado se encuentre frente al juez vuelva a realizar tal acreditación en forma personal.

Es imprescindible que los abogados defensores realicen un exhaustivo análisis de la causa y de las posibilidades de defensa que tiene su cliente y comunicárselo de una forma clara y precisa con la indicación de las ventajas y desventajas que lograría al someterse al procedimiento abreviado, pues, caso contrario perjudicaría la situación de una persona que tiene Derecho a una correcta defensa y comprometiendo de manera irresponsable su prestigio profesional. 


\subsection{Utilización del procedimiento abreviado en delitos penales durante el período 2015 -2016}

En el año 2015 de la totalidad de casos presentados al sistema judicial penal ecuatoriano solamente 12.850 se acogieron al procedimiento abreviado como consecuencia de la sobreutilización de los procedimientos de justicia penal ordinarios, situación que agravó la ya existente congestión del sistema penal.

En el año 2016, 18.233 casos penales hicieron uso del procedimiento abreviado como herramienta legal a través de la cual lograr una resolución expedita capaz de satisfacer las necesidades de las partes en conflicto, cifra de poca significancia tomando en cuenta el elevado número de casos presentados en el sistema judicial penal en dicho período.

Es de destacar que no se ha hecho una buena utilización del procedimiento abreviado debido a su poca difusión entre los abogados en libre ejercicio de la profesión, defensores públicos y funcionarios del sistema judicial penal, considerándose tal herramienta como negativa para los intereses de los abogados en libre ejercicio de la profesión, los cuales al desempeñarse en casos de resolución expedita se ven imposibilitados de exigir mayores remuneraciones.

El afianzamiento de procedimientos de resolución de conflictos judiciales penales ordinarios atenta directamente contra el desarrollo de herramientas legales capaces de agilizar un congestionado sistema judicial penal y brindar una resolución de conflictos rápida y ejecutiva.

\subsection{Elementos del procedimiento abreviado que agilizaron la labor judicial}

El procedimiento abreviado se destaca por ser una herramienta legal capaz de fundamentarse en criterios como la eficacia, celeridad, Economía procesal, juzgamiento en plazos razonables e inexistencia en el uso de medidas cautelares que puedan exceder las posibilidades de respuesta de los órganos del sistema judicial penal.

Debe destacarse que el procedimiento abreviado se revela como un instrumento de defensa social dado que el mismo garantiza el juzgamiento y sanción de los culpables en un breve período, en plena con- 
cordancia con las garantías y Derechos legales, así como los tratados de respeto de Derechos humanos internacionales signados por la nación.

La eficiencia, rapidez y carácter expedito del procedimiento abreviado son características que hacen del procedimiento abreviado la herramienta idónea para accionar y agilizar el aparato punitivo del Estado, el incremento en su utilización garantizará la resolución efectiva del colapso que se verifica actualmente en la administración de justicia penal, es innegable.

También, la característica de autonomía en la voluntad o del consenso del procedimiento abreviado, garantiza que los intervinientes en el conflicto jurídico penal ocupen una posición protagónica, pudiéndose arribar a un acuerdo común a partir del cual se imponga la pena al procesado.

\subsection{Causas por las que el procesado se acogió al procedimiento abreviado}

El procedimiento abreviado brinda al procesado la posibilidad de ahorrar en recursos a ser destinados en el desarrollo de su causa, así como también minimiza el tiempo a ser invertido en el proceso, garantizándose la inaplicación de medidas cautelares como la prisión preventiva.

Igualmente, al llegar a un común acuerdo como resultado del procedimiento abreviado, el procesado garantiza el menor tiempo de condena y del mismo modo cualquier gasto legal en el que pudiese incurrir para garantizar una defensa efectiva.

El procedimiento abreviado brinda la posibilidad que el procesado acceda a un proceso de salida expedita y económica y por ende de mayor eficacia, siendo indudablemente dicho procedimiento la herramienta legal de mayor provecho al procesado, el cual garantizará a través de un acuerdo la menor de las penalidades.

\subsection{Porcentaje de procesos penales aplicables al procedimiento abreviado durante el período 2015 - 2016.}

En el año 2015 del 100\% de los casos penales ingresados, un 30\% no aplicaba al procedimiento abreviado debido a que las penas corres- 
pondientes a dichos actos delictivos excedían los 10 años de privación de libertad o eran delitos de carácter sexual, o delitos que se relacionaban con alteraciones de la seguridad nacional o que violaban los Derechos de la mujer, niños y adolescentes.

Un 70\% de los casos penales presentados en el año 2013, cumplían con los requisitos para ser solucionados mediante el uso del procedimiento abreviado, sin embargo, menos del $10 \%$ de los casos se acogieron a dicho procedimiento, consecuencia directa del desconocimiento del mismo u omisión por parte de abogados en libre ejercicio de la profesión, para garantizar procesos ordinarios prolongados en los que se precise de la utilización de grandes cantidades de recursos económicos aportados tanto por el Estado como por las partes en conflicto.

En el año 2016 del 100\% de los casos penales presentados un 25\% de los mismos no aplicaba al procedimiento abreviado dadas sus características, y del 75\% restante aplicable al procedimiento abreviado solamente un $12 \%$ se acogió al mismo, situación que agravó la congestión de la administración de justicia y afectó los intereses de las partes en conflicto.

Se hace evidente el uso indiscriminado de los procedimientos ordinarios como principal forma de resolución de casos en la justicia penal ecuatoriana, situación que agrava la utilización de los ya limitados recursos económicos del sistema de justicia penal y limita la capacidad del personal legal al momento de lograr mejores resultados en la administración de justicia, reafirmándose de esta forma la insatisfacción existente con el sistema de justicia penal como instrumento de defensa social.

\section{DESARROLLO DE LA PROPUESTA}

\subsection{Exposición de motivos}

El procedimiento abreviado se revela como la herramienta legal capaz de agilizar el aparato punitivo del Estado, garantizando un uso óptimo de recursos humanos y materiales de modo que logrará dar una resolución efectiva al actual congestionamiento del sistema judicial penal con el ahorro de recursos y la reafirmación del principio de autonomía de la voluntad o del consenso. 
Actualmente el sistema penitenciario ecuatoriano no cuenta con los recursos y personal capacitado para lograr una rehabilitación y reinserción de la población penitenciaria a la sociedad en general. La principal misión para el que está proyectado el sistema penitenciario más que para punir a los infractores de la ley es para lograr un cambio y transformación en su conducta de forma tal que reconozcan su error y puedan reincorporarse exitosamente a la sociedad.

La Constitución de la República del Ecuador, en el título IV en el capítulo 4 sección Decimotercera sobre la Rehabilitación Social en su artículo 201 manifiesta que el sistema de rehabilitación social es la herramienta a través de la cual se transforma la conducta de los infractores con el objetivo de evitar su reincidencia, reinserción y adaptación a las normas sociales de forma tal que pueda desarrollar sus potencialidades y transformarse en un elemento útil a la sociedad.

El Art. 51 de la Constitución de la República del Ecuador, en su literal 5 expresa textualmente que entre las funciones del sistema penitenciario ecuatoriano está no solamente velar porque los infractores cumplan su condena, sino que al mismo tiempo el período que transcurran en dichos centros deberá ser utilizado para enriquecer desde el punto de vista productivo, educativo y cultural a los infractores.

Pero debe destacarse que en la actualidad es poca la población carcelaria se encuentra incluida en programas de rehabilitación social, debido en buena medida a la falta de recursos y personal capacitado de las autoridades penitenciarias y, asimismo, también debe destacarse programas de incentivación dirigidos a los reclusos para que transformen sus estándares de vida y formas de comportamiento por lo que la mayoría de los mismos no sienten ningún tipo de motivación para insertarse en programas de rehabilitación e inclusive a ejercer ningún tipo de acciones laborales durante el cumplimiento de la sanción. La mayoría de los internos no realizan tareas o actividades dirigidas a la rehabilitación y reinserción social, en gran medida a la sobrepoblación existente en los centros de rehabilitación social ecuatorianos, con un gran porcentaje de hacinamiento en las mismas. El hacinamiento es la causa principal del agravamiento del comportamiento negativo de la población carcelaria, la cual, el lograr un cambio y transformación positivos empeora su comportamiento adquiriendo nuevos hábitos y conocimientos delictivos que les permite incrementar su capacidad de hacer daño a la sociedad y los transforma en verdaderos criminales. 
Es ahí que se puede afirmar que los centros de rehabilitación ecuatorianos son verdaderas universidades delictivas debido a la poca atención que se presta a los infractores recluidos en las mismas de forma individual, no pudiéndose asignar programas y tareas específicas a cada individuo de tal manera que se logre una transformación verdadera en el carácter de los mismos, así como un cambio en los hábitos y costumbres delictivas, por el contrario, la situación de los internos o personas privadas de la libertad en el presente caos imperante en los mencionados centros del Ecuador, se transforma de mal a peor.

El tema carcelario ha sido una problemática para la mayoría de los gobiernos democráticos de Ecuador debido a los recursos insuficientes que se destinan a dichas instalaciones, las mismas que no cuentan con la infraestructura y elementos necesarios que garanticen el correcto albergue a los detenidos.

También, se debe destacar que el personal carcelario desconoce técnicas de rehabilitación, son inexistentes las estrategias en este sentido y, también es de recalcar que no se efectúan cursos de capacitación y preparación de dicho personal con el objetivo de poder realizar sus funciones de forma óptima y como consecuencia mejorando la situación de orden y disciplina dentro de los centros carcelarios.

Además, las autoridades nacionales han asumido el reto de transformar y construir nuevos centros penitenciarios con el objetivo de mejorar la actual situación de sobrepoblación carcelaria y también potencializar los planes de reinserción social de los infractores, tomando en consideración a los nuevos Centros de Rehabilitación Social, como los de Guayaquil y Latacunga.

Se debe considerar que, a pesar de los actuales esfuerzos de las autoridades por construir nuevos centros penitenciarios con el objetivo de disminuir la sobrepoblación existente, la clave del éxito para lograr una reinserción efectiva de la población carcelaria a la sociedad está en la educación y capacitación del personal de seguridad y rehabilitación penitenciaria, el cual es el principal protagonista en la transformación y cambio positivo de las personas privadas de libertad (PPL).

Una de las falencias mayores del sistema penitenciario en Ecuador, está dada por la deficiente infraestructura de los centros penitenciarios y la poca capacidad existente en los mismos para dar una total cobertura a las necesidades de una población penitenciaria creciente. La 
deficiente puesta en práctica de los programas de rehabilitación social dirigidos a la población penitenciaria es otro factor que no contribuye a la reinserción de los mismos a la sociedad, transformándose en la mayoría de los casos el centro penitenciario en un lugar donde los infractores potencializan sus actitudes antisociales y adquieren nuevas habilidades y destrezas delictivas.

Es de destacar la necesidad imperante de capacitar y formar un nuevo personal penitenciario capaz de asumir los retos actuales con profesionalidad y conocimientos de forma tal que el mismo sea el elemento de peso al momento de lograr una transformación en las actitudes y hábitos de la población penitenciaria.

Por los motivos anteriormente expuestos se recalca la necesidad de impulsar la utilización del procedimiento abreviado, dado que el mismo permitirá una reinserción total del infractor a la sociedad ya que el mismo no deberá pasar extensos períodos en el sistema penitenciario, lo cual permitirá un ahorro de recursos y contribuirá a una reinserción efectiva pues se evitarían actos discriminatorios en su contra.

\section{PROPUESTA DE REFORMA DEL CÓDIGO ORGÁNICO INTEGRAL PENAL}

\section{Asamblea nacional}

\section{Comisión legislativa y de fiscalización}

\section{El pleno de la comisión legislativa y de fiscalización}

\section{Considerando:}

Que: De acuerdo con lo que establece el Artículo 1 de la Constitución de la República del Ecuador, Ecuador es un Estado Constitucional de Derechos y justicia

Que: $\quad$ El Artículo 75 de la Constitución de la República del Ecuador manifiesta que toda persona tiene Derecho a la tutela efectiva, imparcial y expedita de sus Derechos e intereses. 
Que: $\quad$ El Artículo 132 establece que se requerirá de la aprobación de una ley en el caso en que se vaya a tipificar infracciones y establecer las sanciones correspondientes.

Que: $\quad$ El Art.120 numeral 6 de la Constitución de la República del Ecuador establece a la Asamblea Nacional las atribuciones para "Expedir, Codificar, Reformar y derogar las leyes, e interpretarlas con carácter generalmente obligatorio".

Que: $\quad$ La forma de vida actual y el interés colectivo debe prevalecer en la legislación social.

\section{Expide}

La siguiente Ley Reformatoria a la Sección Primera del Título VIII del Código Orgánico Integral Penal referente a los:

Procedimientos Especiales.

Refórmese el numeral 2 del Artículo 635 con el siguiente texto:

I. La propuesta de la o el fiscal será obligatoria y podrá presentarse desde la audiencia de formulación de cargos hasta la audiencia de juicio.

Incorpórese al Art. 635 el siguiente texto:

III.El acuerdo entre el Fiscal y el procesado para confesar la culpabilidad de las acciones ilícitas tendrá como resultado la presentación del cargo que tenga menor penalidad.

IV.En caso de reincidencia del procesado, no se aplicará el procedimiento abreviado encausándose la resolución del conflicto al procedimiento ordinario.

Refórmese el artículo 20 agregándose al final el siguiente texto:

En el caso de acogerse el procesado al procedimiento abreviado, se acumularán las penas hasta un máximo del doble de la pena más leve. 
Refórmese el artículo 21, agregándose al final el siguiente texto:

En el caso de acogerse el procesado; al procedimiento abreviado, se aplicará la pena de la infracción más leve.

\subsection{El procedimiento abreviado en el Derecho comparado}

En el orden nacional de la República Argentina, recientemente se ha incluido el procedimiento abreviado en el sistema penal de este país, de acuerdo con la Ley 24.825.197. El artículo 431 establece que puede requerirse un proceso abreviado que se haya utilizado, si se considera prisión adecuada por un período inferior a seis años, o una pena no relacionada con la privación de libertad, y cuando el acusado, asistido por su abogado, acepta la existencia de su participación en él.

De acuerdo con el Decreto Legislativo No. 51 de 1992, la República de Guatemala ha modificado el sistema de justicia penal al incorporar el proceso de reforma estructural del proceso penal: el Código de Procedimiento Penal de Guatemala establece procedimientos que reducen la pena en el Artículo 464, lo cual es aceptable si el fiscal considera apropiado imponer penas de hasta dos años de prisión, que luego se aumentó a cinco años de prisión en virtud del Decreto $\mathrm{N}^{\circ} 79$ de 1997 o una sanción de encarcelamiento, no libertad.

El Código de Procedimiento de Guatemala, estableció que, si el acusado y su abogado se encontraban de acuerdo con la petición, respecto a la institución y el hecho que, como se describe en la acusación formal, su participación en la comisión de un acto, el artículo 464 permite el uso de un procedimiento abreviado, a uno o más involucrados, incluso si el resto no está de acuerdo.

El segundo párrafo del artículo 465 establece que el veredicto se basará en los hechos descritos en la acusación, pero permitirá que la parte demandada lo incluya a favor de los hechos antes que resulte de la prueba del procedimiento.

Colombia en el año 2004 promulgó un nuevo Código de Procedimiento Penal, que establece procedimientos especiales con sus diferentes anotaciones punitivas, es decir, según cuándo se permite la participación del delito, y debe tenerse en cuenta que en nuestra atención, esta legislación está más desarrollada en la formulación de pro- 
cedimientos especiales, porque de esta manera se implementa efectivamente el propósito propuesto de incluir un procedimiento reducido $\mathrm{y}$ hace que la dependencia judicial sea inocua.

Si el acusado admite su responsabilidad por cometer un delito se beneficiará de una reducción de la multa, si el cargo se realiza entre la acusación y el interrogatorio, es decir, la reducción será de una sexta parte. Cabe señalar que la Ley de Procedimiento Penal de Colombia, no define un acuerdo entre el denunciado y el Ministerio Público ya que el procedimiento abreviado simplemente establece en los acuerdos preliminares y las negociaciones, en una forma similar a un procedimiento abreviado en Ecuador.

\section{CONCLUSIONES Y RECOMENDACIONES}

Una vez realizada la investigación se arriba a las siguientes conclusiones y recomendaciones:

\section{Conclusiones}

El incremento de las actividades delictivas en las últimas décadas del siglo pasado y en la primera del presente siglo se revela conjuntamente con la inaplicación del procedimiento abreviado como las principales causas de congestión del sistema ecuatoriano de justicia.

La función pública del sistema ecuatoriano de justicia se caracteriza por la lentitud y atraso en la resolución de los diferentes conflictos legales a ser solucionados, como consecuencia de la utilización casi exclusiva de procesos judiciales ordinarios, que demandan cifras cuantiosas de recursos económicos, materiales y humanos.

Los recursos económicos, materiales y humanos destinados por el Estado al sistema de justicia ecuatoriano, se revelan como insuficientes para llevar a cabo la totalidad de procesos judiciales ordinarios necesarios para la resolución de conflictos legales.

La mayoría de abogados en libre ejercicio de la profesión desconocen las ventajas y facilidades brindadas por el procedimiento abreviado como herramienta legal facilitadora, debido al uso casi exclusivo de los procedimientos ordinarios. 
Se evidencia que la utilización del procedimiento abreviado como herramienta en la resolución de conflictos penales, garantizará un sensible ahorro de recursos materiales, humanos y de tiempo que incidirán en la descongestión del sistema judicial penal ecuatoriano.

El procedimiento abreviado desde el punto de vista del procesado brinda mayores ventajas que los procedimientos ordinarios de resolución de conflictos penales, al reducirse sensiblemente los recursos económicos a ser utilizados por el mismo, así como el tiempo para obtener una resolución en la reducción de la pena.

El principio de la autonomía de la voluntad de consenso se reafirma con el uso del procedimiento abreviado garantizándose a través del mismo la posición protagónica de los intervinientes en concordancia con la legalidad existente y la determinación en común acuerdo de la pena a imponer al procesado.

\section{Recomendaciones}

Fomentar e incrementar la utilización alternativa del procedimiento abreviado en la resolución de conflictos legales como herramienta de descongestión y agilización del sistema ecuatoriano de justicia.

Mejorar el desempeño de la administración de justicia, a través de la reforma del Código Orgánico Integral Penal en los aspectos referentes al procedimiento abreviado, garantizándose de esta forma la administración expedita de justicia.

Evitar el uso de procedimientos judiciales ordinarios en delitos cuya sanción no exceda la privación de libertad por más de diez años utilizándose en su lugar el procedimiento abreviado como herramienta legal capaz de propiciar la utilización adecuada de recursos económicos, materiales y humanos.

Difundir las ventajas y facilidades brindadas por el procedimiento abreviado como herramienta legal facilitadora de la labor de los fiscales, abogados en libre ejercicio de la profesión y defensores públicos.

Llevar a cabo capacitaciones periódicas dirigidas a abogados en libre ejercicio, y operadores de justicia participantes, en las que se revelen las ventajas y necesidad de incrementar la utilización del proce- 
dimiento abreviado como herramienta legal que incida positivamente en la descongestión del sistema judicial penal ecuatoriano.

Informar a los procesados las ventajas del procedimiento abreviado con respecto a los procedimientos ordinarios de resolución de conflictos penales destacándose la sensiblemente reducción de los recursos económicos a ser utilizados por el mismo, así como el tiempo para obtener una resolución.

Ampliar el principio de la autonomía de la voluntad de consenso con el uso del procedimiento abreviado recalcándose el protagonismo de los intervinientes en concordancia con la legalidad existente.

\section{REFERENCIAS BIBLIOGRÁFICAS}

Aguilera, M. (2010). Teorías compensatorias del Estado. Asunción: Luman.

Arboleda, T. (2010). La Responsabilidad del Estado. Madrid: Cervantes.

Arguedas, J. (2012). Formación de una cultura nacional indoamericana. México D.F.: Siglo Veintiuno.

Carreras, D. (2010). Derechos propios del Estado. Santiago de Chile: Universidad Santa María de Chile.

Castillo, R. (2012). El servidor público español. Madrid: Cervantes.

Delgado, E. (2011). La indemnización como Derecho universal. Caracas: Macmillan.

Delgado, F. (2014). Funciones y funcionarios del Estado. Zaragoza: Océano.

Espinoza, L. (2012). Funcionamiento de la Administración Pública. México D.F.: Azteca.

Estrada, R. (2010). Responsabilidad del Estado. Madrid: Zabalia. 
Ferrero, M. (2010). Historia evolutiva del Derecho. Puerto Barrios: Editorial Oscar de León Palacios.

Fiorini, B. (2009). Relación entre los actos de autoridad y la responsabilidad parcial del Estado. Buenos Aires: Palermo.

Guerrero, J. (2012). La responsabilidad Extracontractual del Estado. México D.F.: Trillas.

Gutierrez, C. (2008). Los Derechos humanos y las responsabilidades del Estado. Buenos Aires: Universidad de Palermo.

Hidalgo, M. (2008). Apuntes de Derecho Administrativo ecuatoriano: Teoría y Práctica. Quito: País.

Linares, J. (2010). La responsabilidad civil del empleado público. México D.F.: Estudios legales.

Marín, M. (2010). Fundamentos del cosntitucionalismo. Manizales: Universidad de Caldas: Ciencias Jurídicas.

Marin, M. (2011). La indemnización por daños y perjuicios. Universidad de Caldas: Manizales.

Mariño, T. (2011). El Derecho administrativo. Bogotá: Patria.

Padilla, A. (2012). La Responsabilidad del Estado. Madrid: Océano.

Portillo, L. (2013). Organización política de la Cultura Hindú. Barcelona: Gran Angular.

Rivera, G. (2010). Derecho de reparación integral. Montevideo: Caspilla.

Rodríguez, A. (2011). Perpectivas de las mutualistas en latinoamerica. Santiago de Chile: Sociedad.

Salgado, J. (2010). Los Derechos indemnizables y su compensación. Aconcagua: Océano.

Sánchez, P. (2011). La responsabilidad contractual del Estado. Quito: Colap. 
Toledo, J. (2011). Pensamiento político de la antigüedad a la modernidad. Buenos Aires: Ceal.

Vallejo, R (2013). La responsabilidad del servidor público. México D.F.: Trillas.

Vonlineur, L. (2014). Sistemas Mutuales . Paris: Rouge Mark.

Zanovini, G. (2010). Derecho Administrativo. México D.F.: Azteca.

Recibido: $15 / 08 / 2017$

Aceptado: 27/11/2017

Dr. Guillermo Enríquez Burbano: Docente titular de la PUCE.

Correo electrónico: genriquezb@puce.edu.ec 